\title{
A New Paradigm for Carbon-Carbon Bond Formation: Aerobic, Copper-Templated Cross-Coupling
}

\author{
Janette M. Villalobos, Jiri Srogl ${ }^{\dagger}$, and Lanny S. Liebeskind ${ }^{\star}$ \\ Emory University, Department of Chemistry, 1515 Dickey Drive, Atlanta, Georgia 30322
}

\begin{abstract}
Thiol esters and boronic acids react to produce ketones under aerobic conditions in the presence of catalytic quantities of a $\mathrm{Cu}^{\mathrm{I}}$ or $\mathrm{Cu}^{\mathrm{II}}$ salt. The reaction occurs at reasonable rates between room temperature and $50{ }^{\circ} \mathrm{C}$ at neutral $\mathrm{pH}$ using thiol esters derived from bulky $2^{\circ}$ amides of thiosalicylamides such as those based on $N$-tert-butyl-2-mercaptobenzamide. In this mechanistically unprecedented reaction system the carbon-carbon bond formation occurs through templating of the thiol ester and the boronic acid at copper; the system is rendered catalytic in copper under the aerobic conditions.
\end{abstract}

\begin{abstract}
We describe herein a mechanistically unprecedented system for the construction of carboncarbon bonds: the copper-templated coupling of a thioorganic and a boronic acid that is rendered catalytic under aerobic conditions. This new reaction type evolved from mechanistically distinct earlier transformations discovered in this laboratory ${ }^{1-3}$ and subsequently extended in others: ${ }^{4-9}$ the anaerobic coupling of a wide range of thioorganics with either boronic acids or organostannanes that require the presence of catalytic quantities of a palladium source and stoichiometric quantities of a $\mathrm{Cu}^{\mathrm{I}}$ carboxylate. In this communication we reveal the unique attributes of the copper-catalyzed, aerobic reaction system applied to the formation of ketones by the coupling of thiol esters with boronic acids at neutral $\mathrm{pH}$.
\end{abstract}

All published thioorganic-boronic acid cross-couplings have required catalytic quantities of $\mathrm{Pd}$ and at least a stoichiometric quantity of a $\mathrm{Cu}^{\mathrm{I}}$ arboxylate (or diphenylphosphinate) as a reaction mediator. Simple balancing of the generic reaction equation reveals the reasons for the latter requirement. The $\mathrm{Cu}^{\mathrm{I}}$ ion pairs with the thiolate in a thermodynamically strong $\mathrm{Cu}$ $\mathrm{SR}$ bond, while a full equivalent of the borophilic carboxylate counterion drives the $-\mathrm{B}$ $(\mathrm{OH})_{2}$ moiety to its thermodynamic sink, $\mathrm{RC}(\mathrm{O}) \mathrm{OB}(\mathrm{OH})_{2}$. This implies that the reaction system could be rendered catalytic in $\mathrm{Cu}$ if a $\mathrm{Cu}$ oxygenate could be regenerated from $\mathrm{Cu}-\mathrm{SR}$. 10 We hypothesized that thioorganic-boronic acid cross-couplings carried out under aerobic conditions in the presence of a second sacrificial equivalent of the boronic acid would achieve the desired goal. The strong Cu-SR bond would be broken by forming a thioether (using the second equivalent of boronic acid ${ }^{11}$ ) and a $\mathrm{Cu}$ oxygenate (of undefined oxidation state) would be released to the system.

To test this hypothesis thiol esters possessing a variety of $S$-pendants were constructed and treated, open to air, with $p$-methoxyphenylboronic acid in DMF in the presence of catalytic $\mathrm{Cu}^{\mathrm{I}}-3$-methylsalicylate, and, in the initial studies, with co-catalytic Pd sources. As shown in Table 1 only those thiol esters possessing appropriately positioned ligating $S$-pendant groups participated in efficient aerobic coupling with boronic acids. Control experiments revealed that

Lanny.Liebeskind@emory.edu.

Current address: Academy of Sciences of the Czech Republic, Institute of Organic Chemistry and Biochemistry, Flemingovo nam. 2 , 16610 Prague, CZECH REPUBLIC 
a palladium co-catalyst was not required under the aerobic reaction conditions making this system mechanistically distinct from our earlier thioorganic-boronic acid couplings. Key observations included: (1) the requirement for a ligating functional group positioned ortho but not para to the S-pendant linkage, (2) the optimum performance of thiol esters derived from bulky $-\mathrm{NH} i$-Pr and $-\mathrm{NH} t-\mathrm{Bu}$ thiosalicylamides (contrast entries 5 and 6 with 7 and 8, Table 1), and (3) the formation of the $S$-arylated pendant in a roughly 1:1 ratio with the desired ketonic product.

The scope of this new aerobic cross-coupling was briefly probed through the reaction of a variety of $S$-acyl- $\mathrm{NH} t$-Bu thiosalicylamides with 2.5 equivalents of a boronic acid and $5 \%$ $\mathrm{Cu}^{\mathrm{I}}-3$-methylsalicylate in DMF at $50{ }^{\circ} \mathrm{C}$ open to air. This study, depicted in Table 2, demonstrates that aromatic, heteroaromatic, and alkenyl boronic acids are suitable reaction partners for aromatic, aliphatic, and $\alpha, \beta$-unsaturated thiol esters. Aldehydic and acetylenic functional groups are tolerated (entries 2 and 9 ) as is modest steric hindrance in the boronic acid (entry 3). Cyclohexylboronic acid, the only aliphatic boronic acid explored in this study, was unreactive.

Control experiments with stoichiometric copper sources under argon suggest the importance of $\mathrm{Cu}$ oxidation states $>1$ in the specific carbon-carbon bond forming step of the overall process: under identical conditions $\mathrm{Cu}^{\mathrm{I}}$-3-methylsalicylate produced less than $20 \%$ of the ketone, while $\mathrm{Cu}^{\mathrm{II}}(\mathrm{OAc})_{2}$ generated the ketone in $60 \%$ yield. In contrast to $\mathrm{Cu}^{\mathrm{II}}(\mathrm{OAc})_{2}$, stoichiometric $\mathrm{Cu}^{\mathrm{II}} \mathrm{Cl}_{2}$ was completely ineffective in promoting the ketone synthesis under argon, further attesting to the importance of partnering an oxygenate counterion with the $-\mathrm{B}(\mathrm{OH})_{2}$ moiety in this coupling. Significantly, using catalytic quantities of $\mathrm{Cu}$ open to air, all $\mathrm{Cu}^{\mathrm{I} X}$ sources explored were effective, regardless of the nature of the counterion $(\mathrm{X}=$ halide, carboxylate, diphenylphosphinate), but only those $\mathrm{Cu}^{\mathrm{II}} \mathrm{X}_{2}$ sources bearing an oxygenate counterion ( $\mathrm{X}=$ carboxylate or diphenylphosphinate, but not halide) were able to initiate and support the aerobic reaction. We propose that $\mathrm{Cu}^{\mathrm{I}}$ must be accessible for effective catalysis. This requires in situ reduction of a $\mathrm{Cu}^{\mathrm{II}}$ pre-catalyst to $\mathrm{Cu}^{\mathrm{I}}$ by the boronic acid, an apparently facile process with an oxygenate but not with a chloride counterion on $\mathrm{Cu}^{\mathrm{II}}$. This is reminiscent of the requirement for an oxygenate counterion to facilitate boron to palladium transmetalation in Miyaura-Suzuki cross-couplings. 12

The mechanism of this aerobic cross-coupling must take into account (1) active catalysis without $P d$, using sources of $\mathrm{Cu}$ only, (2) catalytic turnover under aerobic but not anaerobic conditions, (3) the apparent requirement for accessing $\mathrm{Cu}^{\mathrm{I}}$ during the catalytic cycle, (4) the requirement for a thiol ester bearing a chelating $S$-pendant, and finally (5) the production in a roughly 1:1 ratio of both the desired ketone and the thioether derived from the $S$-pendant and the boronic acid. The absence of palladium in the catalytic sequence and the lack of any precedent for oxidative addition of thiol esters to $\mathrm{Cu}^{\mathrm{I}}$ make a traditional oxidative additiontransmetalation-reductive elimination pathway for this new reaction unlikely. Rather, on the basis of the control experiments we suggest that the thiol ester-boronic acid aerobic crosscoupling occurs through a novel, higher oxidation state, Cu-templated coupling reaction (Scheme 1).

Closely paralleling extensively documented studies of $\mathrm{Cu}^{\mathrm{I}}$-dioxygen reactions, ${ }^{13-17}$ we suggest that the process is initiated by aerobic activation of $\mathrm{Cu}^{\mathrm{I}}$ coordinated to the thiol ester (Stage 1), which generates a higher oxidation state $\mathrm{Cu}^{\mathrm{II} / \mathrm{III}}$ intermediate (both $\mathrm{Cu}^{\mathrm{II}}$ and $\mathrm{Cu}^{\mathrm{III}}$ are accessible through the low-energy interconversion of $\left[\mathrm{Cu}_{2}\left(\mu-\eta^{2}: \eta^{2}-\mathrm{O}_{2}\right]^{2+}\right.$ and $\left[\mathrm{Cu}_{2}(\mu-\right.$ $\left.\left.\mathrm{O}_{2}\right]^{2+}\right) .{ }^{13-17}$ Metal templating by $\mathrm{Cu}^{\mathrm{II} / \mathrm{III}}$ provides simultaneous Lewis acid activation of the thiol ester along with templated delivery of an adjacent nucleophilic organometallic moiety $\left(\mathrm{R}^{2}\right.$ in Scheme 1, either delivered directly from boron, or through the intermediacy of $\mathrm{Cu}$ ) producing the ketone and a higher oxidation $\mathrm{Cu}$-thiolate. The catalytic cyclic is completed by 
reaction of the $\mathrm{Cu}^{\mathrm{II} / \mathrm{III}}$ thiolate with the second (sacrificial) equivalent of the boronic acid. ${ }^{11 \text {, }}$ 18 This would regenerate the requisite $\mathrm{Cu}^{\mathrm{I}}$ for reentry into the catalytic cycle, and remove thiolate ligand from the reaction system by producing the weakly-coordinating $S$-arylation product. Apparently, binding of the chelating thiol ester to the $\mathrm{Cu}$ catalyst significantly modulates its ability to induce undesired side-reactions such as $\mathrm{Cu}$-catalyzed aerobic homocoupling of the boronic acid ${ }^{19}$ and Castro-Stevens-like oxidative dimerization of the terminal alkyne shown in entry 9 of Table 2 .

In its current manifestation, this new aerobic coupling of thiol esters and boronic acids should find utility in applications where highly selective functionalizations of complex molecules are required and where the need for a second equivalent of boronic acid and formation of the thioether side-product are both unimportant. This will be demonstrated in the near future through disclosure of the selective carbon-carbon bond functionalization of small peptides with boronic acids using catalytic $\mathrm{Cu}$ under ambient, aerobic conditions. ${ }^{20}$

\section{Supplementary Material}

Refer to Web version on PubMed Central for supplementary material.

\section{ACKNOWLEDGMENT}

The National Institutes of General Medical Sciences, DHHS supported this investigation through grant No. GM066153. We thank Dr. Paul Reider of Amgen for his interest in and support of our work. Dr. Gary Allred of Synthonix provided the boronic acids and Cu salts used in our studies. We thank our colleague Dr. Jamal Musaev for very stimulating and insightful conversations. JMV thanks the ARCS Foundation for a graduate fellowship.

\section{References}

1. Lory P, Gilbertson SR. Chemtracts 2005;18:569-583.

2. Zhang Z, Liebeskind LS. Org. Lett 2006;8:4331-4333. [PubMed: 16956219]

3. Yang H, Li H, Wittenberg R, Egi M, Huang W, Liebeskind LS. J. Am. Chem. Soc 2007;129:11321140. [PubMed: 17263394]

4. Prokopcová H, Pisani L, Kappe CO. Synlett 2007:43-46.

5. Morita A, Kuwahara S. Org. Lett 2006;8:1613-1616. [PubMed: 16597123]

6. Oumouch S, Bourotte M, Schmitt M, Bourguignon J-J. Synthesis 2005:25-27.

7. Lengar A, Kappe CO. Org. Lett 2004;6:771-774. [PubMed: 14986971]

8. Alphonse F-A, Suzenet F, Keromnes A, Lebret B, Guillaumet G. Org. Lett 2003;5:803-805. [PubMed: 12633076]

9. Alphonse F-A, Suzenet F, Keromnes A, Lebret B, Guillaumet G. Synlett 2002;3:447-450.

10. The use of a catalytic quantity of $\mathrm{Cu}^{\mathrm{I}}$ with a stoichiometric carboxylate additive did not produce a viable reaction system.

11. Taniguchi N. Synlett 2006;9:1351-1354.

12. Miyaura N, Suzuki A. Chem. Rev 1995;95:2457-2483.

13. Mirica LM, Rudd DJ, Vance MA, Solomon EI, Hodgson KO, Hedman B, Stack TDP. J. Am. Chem. Soc 2006;128:2654-2665. [PubMed: 16492052]

14. Hatcher LQ, Vance MA, Narducci Sarjeant AA, Solomon EI, Karlin KD. Inorg. Chem 2006;45:30043013. [PubMed: 16562956]

15. Matsumoto T, Furutachi H, Kobino M, Tomii M, Nagatomo S, Tosha T, Osako T, Fujinami S, Itoh S, Kitagawa T, Suzuki M. J. Am. Chem. Soc 2006;128:3874-3875. [PubMed: 16551071]

16. Lewis EA, Tolman WB. Chem. Rev 2004;104:1047-1076. [PubMed: 14871149]

17. Kim E, Chufán EE, Kamaraj K, Karlin KD. Chem. Rev 2004;104:1077-1133. [PubMed: 14871150]

18. Herradura PS, Pendola KA, Guy RK. Org. Lett 2000;2:2019-2022. [PubMed: 10891219]

19. Demir AS, Reis O, Emrullahoglu M. J. Org. Chem 2003;68:10130-10134. [PubMed: 14682710] 
20. A broad range of peptidyl thiol esters participate in racemization-free $\mathrm{Cu}$-catalyzed aerobic coupling with boronic acids to yield peptidyl ketones. 

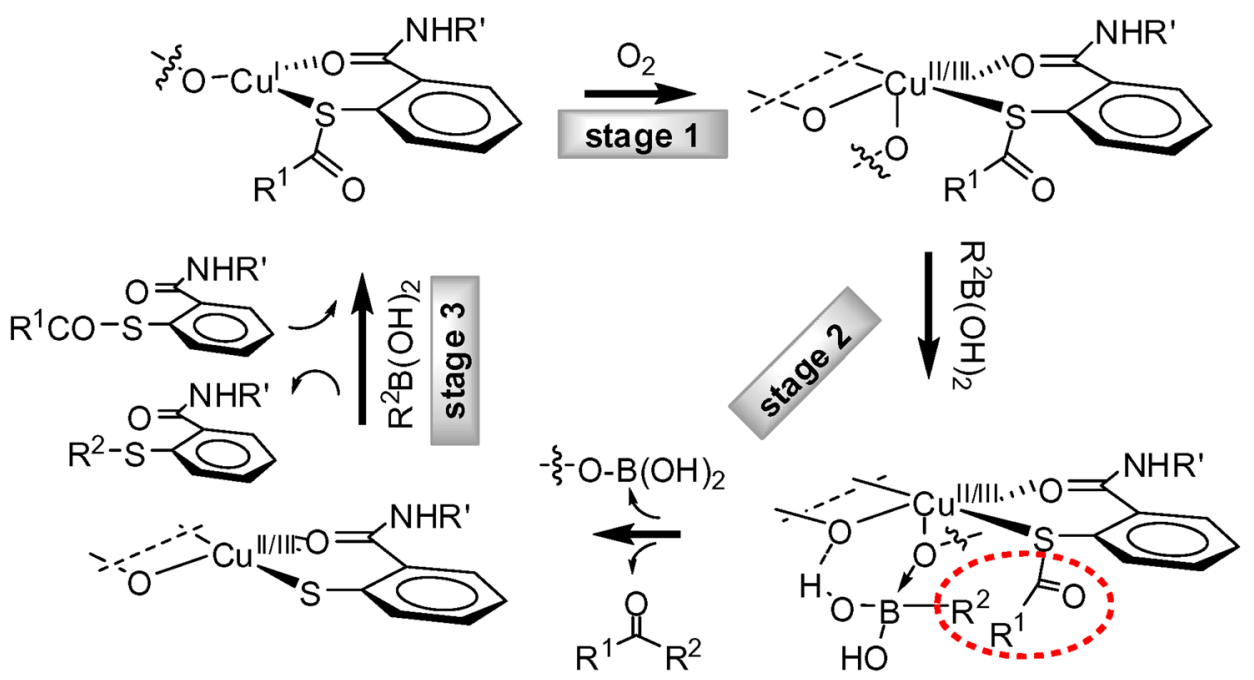

Scheme 1.

Proposed Mechanism 
Table 1

$S$-Pendant Effects in Cu-Catalyzed Aerobic Coupling

\begin{tabular}{|c|c|c|c|c|}
\hline & & - & 1 & \\
\hline entry & pendant & ketone & thioether & biaryl $^{a}$ \\
\hline 1 & $-\mathrm{C}_{6} \mathrm{H}_{5}$ & trace & trace & 57 \\
\hline 2 & $-\left(2-\mathrm{C}_{6} \mathrm{H}_{4} \mathrm{NHCOPh}\right)$ & 6 & trace & 37 \\
\hline 3 & $-\left(\mathrm{CH}_{2}\right)_{2} \mathrm{CONH} t-\mathrm{Bu}$ & trace & trace & 31 \\
\hline 4 & $-\left(2-\mathrm{C}_{6} \mathrm{H}_{4} \mathrm{CONHPh}\right)$ & 34 & $28^{b}$ & trace \\
\hline 5 & $-\left(2-\mathrm{C}_{6} \mathrm{H}_{4} \mathrm{CONmorpholinyl}\right)$ & 30 & $25^{b}$ & 54 \\
\hline 6 & $-\left(2-\mathrm{C}_{6} \mathrm{H}_{4} \mathrm{CONHMe}\right)$ & 32 & $33^{b}$ & trace \\
\hline 7 & $-\left(2-\mathrm{C}_{6} \mathrm{H}_{4} \mathrm{CONH} i-\mathrm{Pr}\right)$ & 77 & 84 & 7 \\
\hline 8 & $-\left(2-\mathrm{C}_{6} \mathrm{H}_{4} \mathrm{CONH} t-\mathrm{Bu}\right)$ & 81 & 75 & 4 \\
\hline
\end{tabular}


Table 2

Aerobic Coupling of Thiol Esters and Boronic Acids

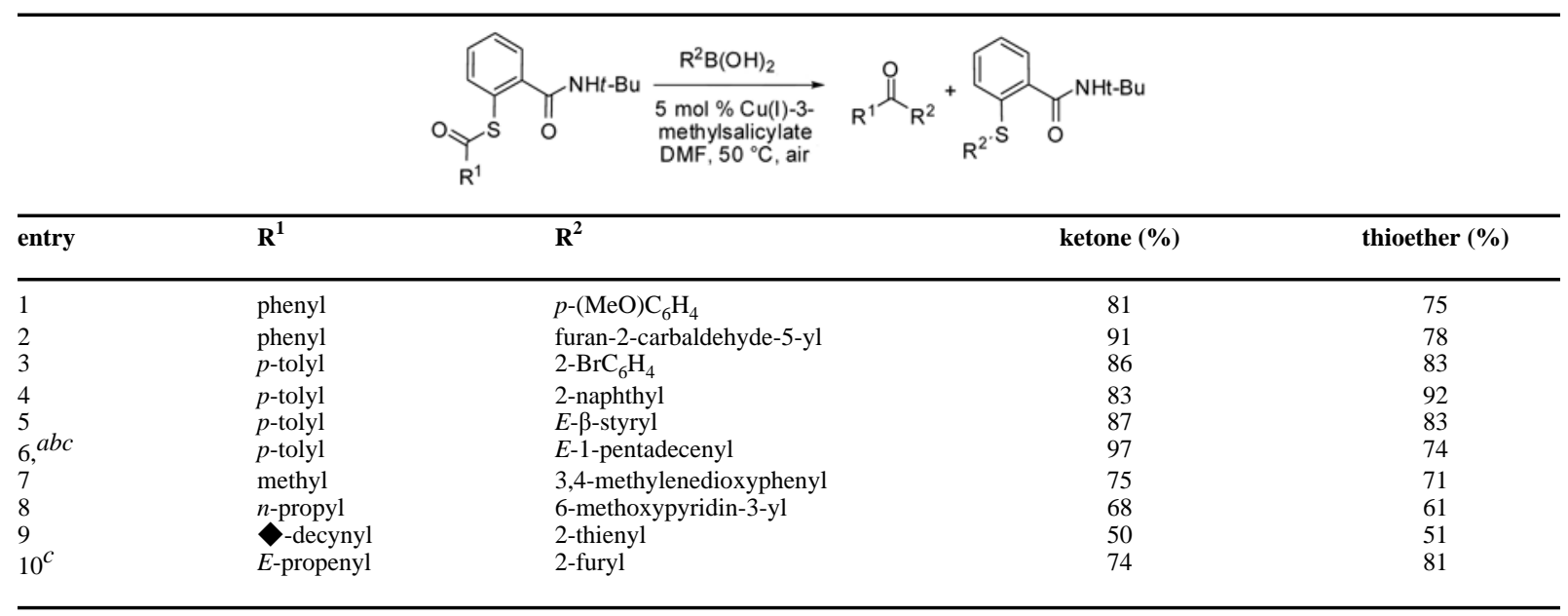

$a_{\text {Propylene oxide was added as a mild acid scavenger to minimize protodeborylation. }}$

${ }^{b} \mathrm{Cu}^{\mathrm{I}}$-2,6-dihydroxycarboxylate was used giving slightly better yields than $\mathrm{Cu}^{\mathrm{I}}$-3-methylsalicylate.

${ }^{c}$ Yield is based on recovered starting material. 